https://doi.org/10.48009/2_iis_2005_16-22

\title{
ANALYTIC HIERARCHY PROCESS AS A DECISION-SUPPORT SYSTEM IN THE PETROLEUM PIPELINE INDUSTRY
}

\author{
Sam Nataraj, Ph.D., Morehead State University, s.nataraj@moreheadstate.edu
}

\begin{abstract}
Analytic Hierarchy Process (AHP) is a decision making algorithm developed by Dr. Saaty. It has many applications as documented in Decision Support System literature. The importance of decisions in the petroleum pipeline industry is reflected in the magnitude and nature of the industry. Worldwide, pipelines transport natural gas, crude oil, and finished petroleum products over long distances within countries and across borders to meet energy needs. Within the United States, natural gas pipelines comprise more than 1.5 million miles of underground transportation pipes. The overall objective in selecting a petroleum pipeline route is the connection of the crude/natural gas source to the refinery or utility company. Obviously, choosing the shortest, most direct route is always a goal for capital expenditure reasons, but many important goals exist simultaneously in the route selection project and at times these goals may conflict [4]. Geophysical, environmental, political, social, economic, and regulatory factors interact to define the route possibilities. This paper looks at AHP as a tool used in petroleum pipe industry to help in decision making.
\end{abstract}

Keywords: Analytic Hierarchy Process, Decision Support System, Petroleum Pipeline Industry, Pipeline Maintenance, Pipeline Construction, Pipeline Route Selection

\section{INTRODUCTION}

Recent research in the application of integrated decision-support systems (DSS) in the petroleum pipeline industry utilizes the analytic hierarchy process (AHP). Research conducted by Dey et al. has focused on decision-support for stages of project planning, particularly as applied within the petroleum pipeline industry. Dey et al. presented a mathematical model for controlling cost, time, and quality of construction projects at the fortieth annual meeting of the Association for the Advancement of Cost Engineering (AACE) Transactions held in Vancouver, British Columbia in 1996. The mathematical model presented in their paper utilizes goal programming for multiple criteria decisions that are inherited in project planning. Optimization goals within project planning can be vague due to the dynamics of forecasting strategic plans [1]. The innate nature of projects is such that forecasts must be connected with the realities of the operational situations, and that usually necessitates change. Within the framework of goal programming, a hierarchical planning model is developed in which the relative effect of the change in one level of activity on other levels of activity is measured. In further research, Dey and others have applied this framework to different aspects of petroleum pipeline projects, using AHP primarily for risk analysis. Mian and Dai [4] apply the analytic hierarchy process broadly to project life cycle, further substantiating the value of AHP as a decision-support system for projects. AHP has been proposed as a multi-criteria decision technique in many industries, including technology for the assessment of decision-support systems [11]. This paper examines the significance of decisions in the petroleum pipeline industry, an overview of AHP, and AHP as applied to the route selection, construction, and maintenance of petroleum pipelines. The discussion of AHP as 
applied to route selection contains an example of an application of AHP, which will serve as the model for discussion of AHP in pipeline construction and maintenance.

\section{SIGNIFICANCE OF DECISIONS IN THE PETROLEUM PIPELINE INDUSTRY}

The importance of decisions in the petroleum pipeline industry is reflected in the magnitude and nature of the industry. Worldwide, pipelines transport natural gas, crude oil, and finished petroleum products over long distances within countries and across borders to meet energy needs. The distances between the source of the petroleum product and the destination for energy processing can be hundreds of miles of varying terrain. This is particularly true as more exploration takes place in more remote areas of the world. Within the United States, natural gas pipelines comprise more than 1.5 million miles of underground transportation pipes [5]. Economies have become dependent upon the smooth flow of petroleum products to meet energy needs [3]. Pipelines carrying petroleum products for extended distances are capital-intensive projects with goals of long life expectancy. The environment in which strategic decisions regarding pipeline planning are made is greatly influenced by external factors [2]. These factors include government regulations, water depth, ground condition, and population growth. Whereas pipeline transportation of petroleum products is considered the safest form of product transportation, the hazardous nature of the product exposes risk for failures leading to environmental disasters and loss of human life [3].

\section{AN OVERVIEW OF AHP}

Analytic Hierarchy Process is a decision-making technique developed in the 1970s by mathematician Thomas L. Saaty, now a professor at the University of Pittsburgh's Katz School [8]. AHP can be used in making decisions that are complex, unstructured, and contain multipleattributes [9]. The decisions that are described by these criteria do not fit in a linear framework; they contain both physical and psychological elements [6]. AHP provides a method to connect that that can be quantified and the subjective judgment of the decision maker in a way that can be measured. In applying AHP to benchmarking, Partovi describes the process in three broad steps: the description of a complex decision problem as a hierarchy, the prioritization procedure, and the calculation of results. AHP is "a method of breaking down a complex, unstructured situation into its components parts; arranging these parts, or judgments on the relative importance of each variable; and synthesizing the judgments to determine which variables have the highest priority and should be acted upon to influence the outcome of the situation" [10]. A problem is put into a hierarchical structure with the level I reflecting the overall goal or focus of the decision [10]. Level II contains factors or criteria for the decision; level III contains subfactors and level IV contains the decision options. The prioritization process is accomplished by assigning a number from a scale developed by Saaty to represent the importance of the criteria. A matrix with pairwise comparisons of these attributes provides the means for calculation. For more complex decisions, Saaty provides examples of Basic, FORTRAN, and APL computer programs in his book published in 1990, Decision Making for Leaders. Expert Choice is software that has been developed by Saaty for AHP application that is used by the United States government and large corporations for complex decisions [8]. 


\section{ANALYTICAL HIERARCHY PROCESS IN PIPELINE ROUTE SELECTION}

The overall objective in selecting a petroleum pipeline route is the connection of the crude/natural gas source to the refinery or utility company. Obviously, choosing the shortest, most direct route is always a goal for capital expenditure reasons, but many important goals exist simultaneously in the route selection project and at times these goals may conflict [4].

Geophysical, environmental, political, social, economic, and regulatory factors interact to define the route possibilities [7]. Poor route selection can be a costly mistake with long-term ramifications for a pipeline operator. An improperly routed pipeline can cause inefficient operations that decrease profitability for years. The analytic hierarchy process has been successfully applied for route selection, enabling the decision makers to connect the subjective and the objective factors involved in the multi-criteria decision. Geographic information system (GIS) technology is integrated into the decision-support system and utilized to provide the alternative routes. In the model presented by Dey and Gupta, four possible routes were identified with attributes defined in a GIS database. In applying the APH model as a problem solving technique, the ultimate hierarchy is the selection of a pipeline route. The intermediate level is composed of the broad goal categories (criteria) of pipeline length, operability, maintainability, approachability, feasibility of construction, and environmental friendliness. Each of these factors has subfactors, which are included in the analysis. Examples of the subfactors include minimizing environmental damage, ensuring accessibility, avoiding obstacles, avoiding routes parallel to high voltage transmission lines, using existing right-of ways if possible, avoiding densely populated areas, and keeping water and rail crossings to a minimum [4]. The scale of relative importance for pairwise comparison as developed by Saaty is shown in Table 1 [10].

Table 1. The Pairwise Combination Scale

\begin{tabular}{lll} 
Intensity & Definition & Explanation \\
\hline 1 & Equal importance & Two activities contribute equally to the object \\
3 & Moderate importance & Slightly favors one over another \\
5 & Essential or strong importance & Strongly favors one over another \\
7 & Demonstrated importance & Dominance of the demonstrated in practice \\
9 & Extreme importance & Evidence favoring one over another of highest \\
& & possible order of affirmation \\
$2,4,6,8$ & Intermediate values & When compromise is needed
\end{tabular}

The judgment of the decision maker is then used to assign values from the pairwise combination scale to each main criterion for a level II analysis. A pairwise comparison matrix using a given example is then developed as shown in Table 2 [4]. In constructing the matrix, the question to be asked as each factor comparison is being made is "how much more strongly does this element (or activity) possess - or contribute to, dominate, influence, satisfy, or benefit - the property than does the element with which it is being compared?" [10]. The first element of the comparison is in the left column and the second element is found in the top row to the right of the first element's row position. A score is assigned indicating the importance of the first element in comparison to the second element. When comparing a factor to itself in the matrix, the 
relationship will always be one. Therefore, there will always be a diagonal of ones in the matrix. A reciprocal relationship exits for all comparisons.

Table 2. Comparison Matrix at Level II

\begin{tabular}{|c|c|c|c|c|c|c|c|}
\hline 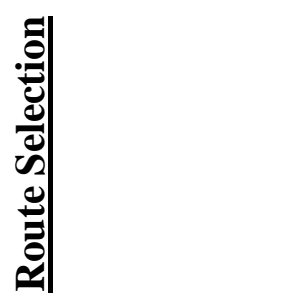 & 윰웜 & 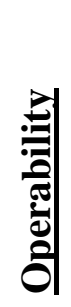 & 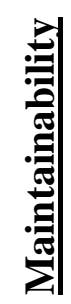 & 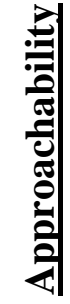 & 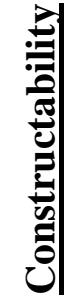 & 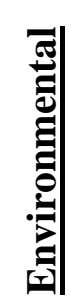 & 참 \\
\hline Length & 1 & 3 & 2 & 5 & 4 & 7 & .28 \\
\hline Operability & $1 / 3$ & 1 & 1 & 3 & 4 & 5 & .19 \\
\hline Maintainability & $1 / 2$ & 1 & 1 & 2 & 3 & 5 & .20 \\
\hline Approachability & $1 / 5$ & $1 / 3$ & $1 / 2$ & 1 & $1 / 2$ & 3 & .13 \\
\hline Constructability & $1 / 4$ & $1 / 4$ & $1 / 3$ & 2 & 1 & 4 & .16 \\
\hline Environmental & $1 / 7$ & $1 / 5$ & $1 / 5$ & $1 / 3$ & $1 / 4$ & 1 & .04 \\
\hline
\end{tabular}

Relative weights are calculated for each factor through a mathematical basis established by Saaty. The process involves "following a path from the top of the hierarchy to each alternative at the lowest level, and multiplying the weights along each segment of the path"[10]. "The outcome of this aggregation is a normalized vector of the overall weights of the options" [10]. The matrix is then repeated in a more extensive format for a level III analysis, applying the weights calculated for the factors in the level II analysis to weights developed for each subfactor as calculated for each alternative route. In the bottom level of the hierarchy (level IV), an aggregate weight is calculated for each pipeline route. The pipeline routes are then ranked by overall weight, with the lowest weight indicating the least risk. The case study applying this methodology to route selection concluded with a route chosen as optimal that was actually longer than two of the other possibilities, but with less risk associated with other factors.

\section{ANALYTIC HIERARCHY PROCESS IN PIPELINE CONSTRUCTION}

The construction of a petroleum pipeline is a complex, extremely capital-intensive project with many decision variables. AHP has been integrated within a decision-support system, creating a framework for the planning phase of pipeline construction. As a response to the limitations of the conventional approaches to project planning, researchers have developed a mathematical model for project planning as applied to a petroleum pipeline project. This model enables project management to "establish an adequate relationship between the essential design parameters (technical requirements, construction schedules, investment planning and related expenditures) and to create reference documents (time schedules, cost estimation and specifications) at the early feasibility states of the project" [1]. The object of procedure is to create an overall project breakdown structure (PBS), which is accomplished through classification of objectives into a work breakdown structure (WBS) and an organization breakdown structure (OBS). It is in the work breakdown structure that AHP is applied in this model to measure risk; this value is then 
incorporated in the project breakdown structure. Typical components of WBS in the construction of a pipeline include pipeline spreads, pump stations, pumping-cum-delivery stations, delivery stations, scraper stations, telecommunication system, survey and field engineering, land acquisition, building and construction [2]. Each component is a work package, which is then broken down into factors and subfactors relative to that overall goal. The same methodology explained in the route selection discussion is applied to each of the work packages, with the factors and subfactors being identified through the analyst's experience or a technique such as Delphi [2]. In this way each work package is then assigned a high, medium, or low total risk. The work breakdown structure is then combined with the organization breakdown structure that has been defined through a traditional matrix structure. The two together form the project breakdown structure, with the level of risk assigned to each work package defining the degree of control for implementation.

\section{ANALYTIC HIERARCHY PROCESS IN PIPELINE MAINTENANCE}

Pipeline maintenance is an important aspect of the petroleum pipeline industry because of the correlation between maintenance with safe and failure-free operations. Historically, maintenance policies have been based on experience but current trends are toward a more organized, proactive methodology [3]. Pipeline operators are utilizing data analysis and in-house studies to target areas of the pipeline for maintenance. This is a task because of the prevailing system lengths. AHP provides a methodology for risk analysis, which, when applied to pipeline failure potential, creates a "cost-effective, customized, flexible, and logical maintenance plan" [3]. The focus of the hierarchy is the probability of failure for a pipeline or pipeline segment. The level I goal is to determine the probability of failure. The level II criteria include likelihood of corrosion, external interference, construction or material defects, or acts of God [3]. Following the procedure for applying the analytic hierarchy process, each factor has subfactors identified at level III. The level III subfactors include, but are not limited, to internal or external corrosion, third-party activity or malicious activity, poor construction or low grade materials, earthquakes, floods, and human or operation error. Pairwise comparisons are made between each level I criterion and then between each level II criterion to establish a risk factor for each pipeline. Level IV is each pipeline segment represented in the analysis. The pipelines are then ranked according to likelihood for failure. At this point, the pipeline identified as most likely to have failure potential can be broken into segments of equal length and the process repeated to further isolate the location most likely to fail. When dividing the pipeline into segments for further analysis, "the length and number of segments should be based upon the similarity of conditions from the point of view of failure probability, instead of arbitrarily dividing the pipeline into four equal segments". It is evident that this type of analysis that allows for comparisons made on a sequentially smaller area can be valuable in isolating areas most likely to fail, creating a proactive maintenance program.

\section{SUMMARY}

The analytic hierarchy process, as developed by Thomas Saaty, has been successfully applied in recent research to cases of project planning, route selection, construction planning, and maintenance in the petroleum pipeline industry. Researchers have integrated AHP with goal programming into a decision-support system for overall project and construction planning. The 
nature of project planning is dynamic and AHP allows for measuring the effect of change. AHP has been integrated into a decision-support system with geographic information system technology for route selection, creating a methodology for decision optimization in the existence of conflicting goals. Pipeline maintenance has traditionally been "hit or miss" or reactive due to the vastness of the systems. AHP, as applied to pipeline maintenance, offers a highly effective, proactive method of isolating areas of most likelihood for failure. There are two primary benefits for application of AHP in this research which would be applicable to any industry. AHP is a technique for the breaking down a complex problem with many factors by relating pairs of factors. In relating the factors, quantitative analysis and the subjective judgment of the decision makers can be connected.

\section{REFERENCES}

1. Dey, P. K., Tabucanon M.T., \& Ogunlana S.O. (1996a). A Decision Support System for Project Planning. 1996 Transactions of AACE (Association for the Advancement of Cost Engineering) International: Proceedings of the 40th meeting, Vancouver, British Columbia, 23-26 June, 1996. Baltimore: AACE International.

2. Dey, P. K., Tabucanon M.T. \& Ogunlana S.O. (1996b). Petroleum Pipeline Construction Planning: A Conceptual Framework. International Journal of Project Management, 14(4), 231-240.

3. Dey, P. K., Ogunlana S.O., Gupta S.S. \& Tabucanon M.T. (1998). A Risk-Based Maintenance Model for Cross-Country Pipelines. Cost Engineering, 40(4), 24-30.

4. Dey, P. K. \& Gupta S.S. (1999). Decision Support System for Pipeline Route Selection. International Journal of Project Management, 41(10), 29-35.

5. Kalisch, B. (1999). Achieving Common Ground. American Gas, 81(8), 28-29. Journal online. Available from ABI/Inform, accession no. 10878177.

6. Mian, S.A. \& Dai C.X. (1999). Decision-Making Over the Project Life Cycle: An Analytical Hierarchy Approach. Project Management Journal, 30(1), 40-52.

7. Montemurro, D., Barnett S. \& Gale T. (1998). GIS-Based Process Helps TransCanada Select Best Route for Expansion Line. Oil \& Gas Journal, 96(25), 63-71. Journal on-line. Available from ABI/Inform, accession no. 01656557.

8. Palmer, B. (1999). Click Here for Decisions. Fortune, 139(9), 53-16. Journal on-line. Available from ABI/Inform, accession no. 01807687.

9. Partovi, F.Y. (1994). Determining What to Benchmark: An Analytic Hierarchy Process Approach. International Journal of Operations \& Project Management, 14(Jun), 25-39. Journal on-line. Available from ABI/Inform, accession no. 00915975.

10. Saaty, T. L. (1990). Decision Making for Leaders. Pittsburgh: RWS Publications.

11. Santhanam, R. \& Guimaraes T. (1995). Assessing the Quality of Institutional DSS. European Journal of Information Systems, 4(3), 159-170. 